\title{
Interim Federal Health Program for Refugees: Looking Back and Moving Forward
}

\author{
Hamid Abdihalim, BSc ${ }^{1}$ \\ ${ }^{1}$ Dalhousie Medical School
}

A B STRACT

Refugee health continues to be an important topic in domestic and foreign affairs. In Canada, the interim federal health program (IFHP) is what provides refugees with healthcare insurance. Since 2012, there have been a series of changes to the IFHP. Due to the precarious status of the IFHP over the past few years, there have been a number of challenges associated with it. This commentary provides a review of the IFHP's history, outlines specific challenges that remain within the program, and puts forward potential solutions to those challenges.

RÉ S U É

La santé des réfugiés continue d'être un sujet important dans les affaires domestiques et étrangères. Au Canada, le programme fédéral de santé intérimaire (PFSI) est responsable de fournir l'assurance maladie aux réfugiés. Depuis 2012, il y a eu une série de changements au PFSI. Étant donné l'état précaire du PFSI au cours des dernières années, il existe un certain nombre de défis qui y sont associés. Ce commentaire fournit un aperçu de l'histoire du PFSI, souligne les défis précis qui persistent dans le programme, et propose des solutions potentielles à ces défis.

\section{INTRODUCTION}

The ongoing Syrian conflict has created the world's largest humanitarian crisis since the Second World War. Since the start of the conflict, millions of Syrian citizens have been forcibly displaced, including over 4 million refugees [1]. Canada has taken positive steps to address this crisis, such as sponsoring over 25,000 Syrian refugees to migrate to the country. When the federal government sponsors refugees, the goal is not to simply get them onto Canadian soil, but also to provide them with appropriate support to help them integrate into society. This includes access to adequate physical and mental healthcare services, which together are provided through the interim federal health program (IFHP).

\section{THE IFHP - OVERVIEW \& HISTORY}

During the Second World War, the world experienced an immense humanitarian crisis resulting in millions of people fleeing their countries of origin. In the aftermath of the war, capable nations, such as Canada, experienced an influx of refugees from around the globe.

The Canadian federal government in the 1950s acknowledged that refugees faced considerable difficulties integrating and establishing themselves. Furthermore, it became clear that refugees with emergency health concerns were frequently unable to afford the healthcare that they required. Since universal healthcare in Canada was not yet established, many refugees with traumatic and sometimes violent experiences did not receive even the most basic primary care. To address this issue, in 1957 the federal government established the IFHP. The IFHP mandated the federal government to provide temporary essential healthcare insurance to refugees and other newcomers to Canada [2]. From 1957 to 1995 the IFHP was managed by the Department of National Health and Welfare and since 1995, the IFHP has been managed by Citizenship and Immigration Canada $[2,3]$.

In April 2012, the federal government announced planned changes to the IFHP as a way to decrease spending in this sector. The federal government purported it would save around \$20 million through cost cutting measures [4-6]. According to some researchers, however, those costs would merely trickle down to provincial health budgets [4-6]. For instance, by not having access to primary care through the IFHP, refugees presented to emergency departments, at the expense of the provinces, with health concerns that could otherwise have been dealt with earlier and at a lower cost [4-6].

The planned changes to the IFHP took effect in June 2012. As a result, healthcare coverage for many refugees was eliminated and other refugees received significantly reduced coverage. Prior to this, the IFHP had provided equal healthcare coverage to all eligible refugees. With the 2012 cuts, different categories of beneficiaries were created based on refugee status and healthcare coverage was provided based on those categories. For example, government assisted refugees maintained full IFHP coverage, 
while privately sponsored refugees and refugee claimants lost all medication coverage $[2,6]$. Most refugee claimants were still covered for medical services, the exceptions being those from designated countries of origin that were considered safe by the federal government $[2,5,6]$. Under the 2012 IFHP, refugees from these countries lost all coverage except for benefits that were considered a public health and safety concern [2,6]. Further categorization of refugees was integrated into the revised IFHP, dividing the refugee population into eleven groups and providing four different levels of healthcare coverage $[2,6]$. Without IFHP coverage or only partial coverage, refugees would effectively lose all or part of their sole form of healthcare insurance.

On July 4, 2014, a federal court struck down the 2012 revisions to the IFHP $[2,3,7]$. According to the court, these revisions breached sections 12 and 15 of the Charter of Rights and Freedoms $[2,3,7]$. The court considered the cuts to be "cruel and unusual treatment" as they intentionally set out to make the lives of an already vulnerable population even more difficult $[2,3,7]$. The federal government decided to appeal the court's decision and in the meantime, it restored parts of the IFHP, but still provided considerably less coverage than had previously been available $[2,3,7]$. With the November 2014 revisions, two additional refugee categories were created bringing the total to 13 , and one additional health benefit category was created for a total of five different levels of coverage. This made the 2014 version of the IFHP arguably more complicated than the 2012 version $[2,6]$.

October 19, 2015 saw the election of a new federal government in Canada. In December 2015, the newly elected government took initial steps to restore the IFHP to its pre-2012 state by dropping the federal government's appeal of the 2014 court decision. In February 2016, the federal government announced it would fully restore the IFHP by April 2016 [8]. It also decided to expand on aspects of the program relating to overseas management of refugee healthcare by April 2017 [8]. As of now, the IFHP again offers full healthcare coverage to all refugees equally [8].

\section{CONSEQUENCES OF THE CHANGES TO THE IFHP}

From the 2012 cuts to the IFHP, to their subsequent reversal in 2016, there have been both positive and negative developments. Among the positive developments are the consolidated efforts of people and organizations from both inside and outside the medical community to stand with our refugee population. These efforts led to the eventual restoration and expansion of the IFHP along with important research demonstrating the importance of such a program $[2,6]$

Negative consequences include decreased funding, resulting in significant direct health consequences for specific individuals who lost their IFHP coverage $[2-4,6,7]$. Additionally, owing to the manufactured complexity of the IFHP's reimbursement scheme, some healthcare professionals have accepted refugee patients and charged them directly for services to which they were entitled $[2,4,7,9]$. There is also considerable confusion among healthcare professionals about the working of the IFHP stemming from the multiple changes over the years $[2,4,7,9]$. This has led some healthcare professionals to not take on refugee patients because of uncertainty as to whether or not they will be reimbursed for their services $[2,4,7-9]$. Lastly, while the restored IFHP is less complex than IFHP 2012 or 2014, accessing the IFHP can be burdensome for healthcare professionals (e.g., registration requirements) who take on refugee patients $[2,4,7-10]$.

\section{POTENTIAL SOLUTIONS}

The first step in addressing some of the problems with the IFHP was to restore the program to its pre-2012 capacity. In doing so, adequate resources were made available and the complexity of the IFHP was reduced by eliminating all categories of refugees and available health care services. With these measures in place, the federal government is now well placed to take steps to address two further problems; confusion among healthcare professionals about the working of the IFHP, and the excessive burden it places on healthcare professionals.

Regarding the confusion surrounding the IFHP, when healthcare professionals are unsure who is covered and to what extent they are covered, refugee patients with IFHP coverage may be charged for services that they are entitled to and sometimes may be refused care $[2,4,7-10]$. If the federal government can implement policies that simplify the IFHP's complicated registration and reimbursement schemes it may help healthcare professionals better understand the IFHP and what it entails. Furthermore, an awareness campaign by the federal government, targeting healthcare professionals specifically, may be useful in communicating the current IFHP policy in place. The government can benefit from working with provincial and national healthcare associations, as well as colleges, in communicating with healthcare professionals around the country.

Regarding the burdens imposed on healthcare professionals with the IFHP, it is important to understand how the registration and reimbursement scheme continues to deter healthcare professionals from taking on refugees as patients $[2,4,7-10]$. If a healthcare professional wants to take on refugee patients that use the IFHP, they must first become a Medavie Blue Cross registered provider [10]. They must then ensure that their patients are covered by the IFHP each time they see them [10]. The additional paperwork and time commitment involved in registering for the IFHP, along with waiting to receive reimbursement, has resulted in some clinics refusing patients with IFHP coverage [2,4,7-10]. Establishing a simple, easy to navigate system where healthcare 


\section{Commentary}

professionals are not burdened in registering for the program or receiving reimbursement for their work could be a potential solution. Details regarding IFHP registration and reimbursement policy should be made in consult with healthcare professionals who are directly involved in utilizing the IFHP and caring for refugee patients.

\section{SUMMARY}

Since its establishment in 1957, the IFHP has provided temporary essential healthcare insurance to refugees and other newcomers to Canada. With the 2012 and 2014 changes to the IFHP, numerous challenges developed. First, the federal government significantly decreased program funding. Second, there was increased complexity of the program as a result of the changes made to its funding scheme. Third, there was increased confusion among healthcare professionals resulting from this complexity, as well as the frequent changes to the program. Last, the registration and reimbursement processes were made more burdensome for refugees and health care providers. In 2016, a new federal government returned the IFHP to its pre-2012 capacity by restoring its funding and eliminating the categorization of refugees. The government also went on to expand certain provisions within the IFHP. With these measures in place, the federal government is now ready to take further steps in addressing the remaining challenges. These challenges include the continued confusion surrounding the Federal Program and the excessive burden it places on health care providers who service patients insured under the program.

To address these challenges, the federal government can work with provincial and national medical associations to create an awareness campaign about what the IFHP entails, how it can be accessed, who is covered, and to what extent they are covered. The government should also work to simplify the IFHP's registration and reimbursement processes to reduce the burden placed on healthcare providers who are trying to take on refugee patients.

\section{REFERENCES}

1. Government of Turkey. Syria Regional Refugee Response [Internet]. Ankara (TR): United Nations High Commissioner for Refugees; 2016 [cited 2016 July 20]. Available from: http://data.unhcr.org/syrianrefugees/regional.php.

2. Ruiz-Casares M, Cleveland J, Oulhote $Y$, et al. Knowledge of Healthcare Coverage for Refugee Claimants: Results from a Survey of Health Service Providers in Montreal. PLoS One. 2016;11(1):20.

3. Mactavish A. Canadian Doctors for Refugee Care v. Canada (Attorney general) [Internet]. Ottawa (ON): Canadian Legal Information Institute; 2014 July 4 [cited 2016 July 20]. Available from: http://canlii.ca/t/g81sg.

4. Chen YY. Ontario right to fix Ottawa's mistake on refugee health care. [Internet]. Toronto (ON): Toronto Star; 2013 Dec 12 [cited 2016 July 22] Available from: https://www.thestar.com/opinion/commentary/2013/12/12/ontario right to fix ottawas mistake on refugee health care.html.

5. Stanbrook MB. Canada owes refugees adequate health coverage. CMAJ. 2014;186(2):91.

6. Barnes S. The Real Cost of Cutting The Interim Federal Health Program.
Wellesley Institute. 2013;1-19.

7. Webster PC. Many refugees still denied care despite ruling. CMAJ. 2015;187(10): E307-8.

8. Keung N. Ottawa to restore and expand refugee health benefits [Internet]. Toronto (ON): Toronto Star; 2016 Feb 18 [cited 2016 July 23] Available from: https://www.thestar.com/news/immigration/2016/02/18/ottawa-to-restore-and-expand-health-care-for-refugees.html.

9. Eggertson L. Optimism for restoration of refugee health care. CMAJ. 2016;188(1): E1.

10. Government of Canada. Interim Federal Health Program - Information for health-care professionals [Internet]. Ottawa (ON): Government of Canada: Immigration and citizenship; 2016 [cited 2016 July 23]. Available from: http://www.cic.gc.ca/english/refugees/outside/arriving-healthcare/practitioners.asp. 